\title{
A GEOMETRIC PROOF OF BLUNDON'S INEQUALITIES
}

\author{
DORIN ANDRICA AND CATALIN BARBU
}

Abstract. A geometric approach of Blundon's inequality is presented. Theorem 2.1 gives the formula for $\cos \widehat{I O N}$ in terms of the symmetric invariants $s, R, r$ of a triangle, implying Blundon's inequality (Theorem 2.2). A dual formula for $\cos \widehat{I_{a} O N_{a}}$ is given in Theorem 3.1 and this implies the dual Blundon's inequality (Theorem 3.2). As applications, some inequalities involving the exradii of the triangle are presented in the last section.

Mathematics subject classification (2010): 26D05; 26D15; 51N35.

Keywords and phrases: Euler's inequality; fundamental triangle inequality; Euler determination problem; dual fundamental triangle inequality.

\section{REFERENCES}

[1] Andreescu, T., AndricA, D., Complex Number from A to..Z, Birkhauser, Boston-Basel-Berlin, 2006.

[2] Andrica, D., Nguyen, K.L., A note on the Nagel and Gergonne points, Creative Math.\& Inf., 17 (2008).

[3] Blundon, W.J., Inequalities associated with the triangle, Canad. Math. Bull. 8 (1965), 615-626.

[4] CourT, N.A., A second course in plane Geometry for Colleges, Johnson Pub. Company, Richmond, 1925.

[5] Coxeter, H.S.M., Greitzer, S.L., Geometry Revisited, The Mathematical Association of America, New Mathematical Library, 19, 1967.

[6] Dospinescu, G., Lascu, M., Pohoaţă, C., Tetiva, M., An Elementary proof of Blundon's Inequality, JIPAM, 9 (2008).

[7] Emelyanov, L., Emelyanov, T., Euler's Formula and Poncelet's Porism, Forum Geom. 1 (2001), $137-140$.

[8] EUlER, L., Solutio facilis problematum quorundam geometricorum difficillimorum, Novi Comm. Acad. Scie. Petropolitanae 11 (1765); reprinted in Opera omnia, serie prima, vol. 26 (ed. by A. Speiser), 139-157.

[9] Guinand, A., Euler lines, tritangent centers, and their triangles, Amer. Math. Monthly, 91 (1984), 290-300.

[10] Johnson, R.A., Advanced Euclidean Geometry, Dover Publications, New York, 1960.

[11] Lalescu, T., The Geometry of triangle (Romanian), Ed. Tineretului, Bucharest, 1958.

[12] Mitrinović, D.S., PeČarić, J.E., Volenec, V., Recent advances in geometric inequalities, Kluwer Acad. Publ., Amsterdam, 1989.

[13] Niculescu, C.P., A new look at Newton's inequality, Journal of Inequalities in Pure and Applied Mathematics, 1, 2 (2000), article 17.

[14] Niculescu, C.P., On the algebraic character of Blundon's inequality, in Inequality Theory and Applications (Y.J. Cho, S.S. Dragomir and J. Kim, Editors), Vol. 3, pp. 139-144, Nova Science Publishers, New York, 2003.

[15] Rouché, É. And Ramus, Question 233, Nouv. Ann. Math., 10 (1851), 353-355.

[16] Satnoianu, R.A., General power inequalities between the sides and the crumscribed and inscribed radii related to the fundamental triangle inequality, Math. Inequal. Appl.,5, 4 (2002), 745-751.

[17] Scimemi, B., Paper-folding and Euler's theorem revisited, Forum Geom. 2 (2002), 93-104.

[18] Sмith, G.C., Statics and moduli space of triangles, Forum Geom. 5 (2005), 181-190. 
[19] STERn, J., Euler's triangle determination problem, Forum Geom. 7, 1-9(2007).

[20] Wu, S., A sharpened version of the fundamental triangle inequality, Math. Inequal. Appl., 11, 3 (2008), 477-482.

[21] YIU, P., Conic Solution of Euler's Triangle Determination Problem, Journal for Geometry and Graphics, 12, 1 (2008), 75-80. 